\title{
v.48, n.3, 2012
}

- Page 513

Change the duplicated TABLE II for TABLE III as follow bellow or change the following reformulated page.

TABLE III - Classification of waste in accordance with CONAMA resolutions No. 358 and ANVISA RDC 306

Group A

Group B

Group C

Group D

Group E
Waste with the possible presence of biological agents. This group is subdivided into 5 classes: A1, A2, A3, A4 and A5.

Waste containing chemical substances with flammable, corrosive, reactive and toxic characteristics.

Material resulting from human activities that contain radionuclides in quantities greater than the limits.

Waste that does not present risk, for example, domestic waste.

Puncturing, cutting or scarifying materials, for example: needles, scalpel blades, lancets, micro-pipettes, pipettes, Petri dishes) 
TABLE II - Classification of waste

\begin{tabular}{lll}
\hline Class & Classification & Description \\
\hline Class I & Hazardous & $\begin{array}{l}\text { Waste, which because of their physical, chemical or infecto-contagious properties, may } \\
\text { present risks to public health. For example: products with flammable, corrosive, reactivity, } \\
\text { toxicity and pathogenicity characteristics. }\end{array}$ \\
\hline Class II & Non-hazardous & The non-hazardous waste was listed in the ABNT NBR 10.004. \\
\hline Class II A & Non-inert & $\begin{array}{l}\text { Those who do not fit the classifications of Class I waste - Hazardous waste or class II } \\
\text { B - inert. The residue class II - not inert may have properties such as biodegradability, } \\
\end{array}$ \\
& combustibility or water solubility. \\
\hline Class II B & Inert & $\begin{array}{l}\text { Any residues that, when sampled in a representative and subjected to a dynamic and } \\
\text { static contact with distilled or deionized water at room temperature, do not have any of } \\
\text { its constituents dissolved concentrations exceed the standards of potable water, except } \\
\text { for appearance, color, haze, hardness and flavor. }\end{array}$ \\
& &
\end{tabular}

TABLE III - Classification of waste in accordance with CONAMA resolutions No. 358 and ANVISA RDC 306

\begin{tabular}{ll}
\hline Group A & Waste with the possible presence of biological agents. This group is subdivided into 5 classes: A1, A2, A3, \\
A4 and A5. & Waste containing chemical substances with flammable, corrosive, reactive and toxic characteristics. \\
Group B & Material resulting from human activities that contain radionuclides in quantities greater than the limits. \\
Group D & Waste that does not present risk, for example, domestic waste. \\
Group E & $\begin{array}{l}\text { Puncturing, cutting or scarifying materials, for example: needles, scalpel blades, lancets, micro-pipettes, } \\
\text { pipettes, Petri dishes) }\end{array}$ \\
\hline
\end{tabular}

TABLE IV - Classification of the types hazardous medication waste

\begin{tabular}{ll}
\hline Type 1 & Hazardous medication that wasn't used, was partially used, is expired or cannot be used \\
& Hazardous medication originating from spills, as well as containment, absorption, removal and cleaning \\
& material contaminated by them \\
& HEPA filters from safety cabins where hazardous medication is handled \\
& Infusion pockets and equipment, filled or partially used, and other non-empty containers containing solutions \\
& of hazardous medications over the established limits \\
\hline Type 2 & Empty containers, including primary packages, when they are completely empty (for example: bottles, vials, \\
& pill blisters) and equipment, utensils or disposable devices \\
& Personal Protective Equipment originating from the handling and preparation of hazardous medications and \\
& routine activities \\
& Surface, workbench and safety cabin liners that had no direct contact with hazardous medications
\end{tabular}

guarantee safety, minimizing environmental impacts (Pinto et al., 2009).

Class I Hazardous Waste Landfill: Technique for the disposal of chemical waste in the soil, using specific engineering procedures for its confinement, without causing damage or risk to public health and reducing environmental impact (Pinto et al., 2009).

The sanitary landfill norms are dealt with especially by ABNT NBR norm No. 13.896, of July 30 of 1997 , which deals with Non-hazardous waste landfills - Criteria for the project, implementation and operation; CONAMA RESOLUTION No. 313, of October 29, 2002 / ANNEX III, which Regulates the national industrial solid waste inventory; ABNT NBR 8418 and NBR 842 Abridgement on the Presentation of hazardous industrial waste landfill projects and ABNT NBR 1057 and NBR 1025 Abridgement on the Hazardous waste landfills - Criteria for the project, construction and operation.

Co-processing: is the thermal destruction of waste in cement kilns. Its difference in relation to other burning 